\title{
PARCELAMENTO DE FÓSFORO EM ALGODOEIRO IRRIGADO ${ }^{1}$
}

\author{
Leonardo Angelo de Aquino ${ }^{2}$, Paulo Geraldo Berger ${ }^{3}$, \\ Júlio César Lima Neves ${ }^{4}$, Tricia Costa Lima ${ }^{3}$, Rosiane Filomena Batista Almeida de Aquino ${ }^{2}$
}

\begin{abstract}
PHOSPHORUS SPLIT

APPLICATION ON IRRIGATED COTTON

Most regions where cotton is cultivated in Brazil present low soil fertility, especially concerning the available phosphorus (P). This study aimed to evaluate the phosphorus split application on irrigated cotton, for reaching a higher phosphate fertilization efficiency, in comparison to the traditional application at sowing. The experiment was conducted in Quartzarenic Neosol with $22 \mathrm{mg} \mathrm{dm}^{-3}$ of $\mathrm{P}$ (medium availability), in the north region of the Minas Gerais State, Brazil. The design used was randomized blocks, in a $(4 \mathrm{x} 3)+3$ factorial scheme, with three replications. Treatments consisted of $\mathrm{P}_{2} \mathrm{O}_{5}$ doses $\left(0 \mathrm{~kg} \mathrm{ha}^{-1}, 30 \mathrm{~kg} \mathrm{ha}^{-1}, 60 \mathrm{~kg} \mathrm{ha}^{-1}, 120 \mathrm{~kg} \mathrm{ha}^{-1}\right.$, and $\left.180 \mathrm{~kg} \mathrm{ha}^{-1}\right)$ and three split applications ( $80 \%$ and $20 \% ; 60 \%$ and $40 \% ; 40 \%$ and $60 \%$ of the $P$ dose applied respectively at sowing and at 35 days after emergence (DAE)), plus the application of $0 \mathrm{~kg} \mathrm{ha}^{-1}, 60 \mathrm{~kg} \mathrm{ha}^{-1}$, and $120 \mathrm{~kg} \mathrm{ha}^{-1}$ of $\mathrm{P}_{2} \mathrm{O}_{5}$ at sowing. The $\mathrm{P}$ source was the granulated triple superphosphate, and the $\mathrm{P}$ content in the shoots increased according to the doses applied. Nutrient contents in the index leaf, except for P, were not influenced by P levels and split applications. The $\mathrm{P}$ content in the index leaf and the number of cotton bolls per plant increased with the increment of $\mathrm{P}$ doses, but were not affected by the phosphate fertilizer split application. The application of $40 \%$ of the $\mathrm{P}$ dose at sowing and the remaining amount split at 35 DAE decreased the cotton boll yield, with no significant effect for the other split applications.
\end{abstract}

KEY-WORDS: Gossypium hirsutum L.; cotton boll; phosphate fertilizing.

\section{INTRODUÇÃO}

A pobreza química e a acidez dos solos do Cerrado podem reduzir a produtividade do algodoeiro, se medidas adequadas de correção e adubação não forem adotadas.

O conteúdo de fósforo $(\mathrm{P})$ é limitado em solos ácidos, como os de Cerrado, tornando-se indisponí-

\section{RESUMO}

A maioria das regiões de cultivo de algodoeiro no Brasil apresenta baixa fertilidade dos solos, especialmente com relação ao fósforo $(\mathrm{P})$ disponível. Objetivou-se avaliar a aplicação parcelada de doses de $\mathrm{P}$ em algodoeiro irrigado, visando a uma maior eficiência da adubação fosfatada, em comparação com a aplicação tradicional, em semeadura. $\mathrm{O}$ experimento foi desenvolvido em Neossolo Quartzarênico com $22 \mathrm{mg} \mathrm{dm}^{-3}$ de P (disponibilidade média), no norte de Minas Gerais. Utilizou-se delineamento em blocos ao acaso, em arranjo fatorial $(4 \times 3)+3$, com três repetições. Os fatores estudados foram doses de $\mathrm{P}_{2} \mathrm{O}_{5}$ $\left(0 \mathrm{~kg} \mathrm{ha}^{-1}, 30 \mathrm{~kg} \mathrm{ha}^{-1}, 60 \mathrm{~kg} \mathrm{ha}^{-1}, 120 \mathrm{~kg} \mathrm{ha}^{-1}\right.$ e $\left.180 \mathrm{~kg} \mathrm{ha}^{-1}\right)$ e três formas de aplicação parcelada ( $80 \%$ e $20 \% ; 60 \%$ e $40 \%$; $40 \%$ e $60 \%$ da dose do fertilizante aplicada em semeadura e aos 35 dias após a emergência (DAE), respectivamente), além da aplicação de $0 \mathrm{~kg} \mathrm{ha}^{-1}, 60 \mathrm{~kg} \mathrm{ha}^{-1}$ e $120 \mathrm{~kg} \mathrm{ha}^{-1}$ de $\mathrm{P}_{2} \mathrm{O}_{5}$ na semeadura. A fonte de $\mathrm{P}$ foi o superfosfato triplo granulado e houve aumento no conteúdo de $P$, na parte aérea, em função das doses aplicadas. Os teores de nutrientes na folha índice, exceto $P$, não foram influenciados pelas doses de $\mathrm{P}$ e pelos parcelamentos. O teor de $\mathrm{P}$ na folha índice e o número de capulhos por planta aumentaram com o incremento das doses de $\mathrm{P}$, mas não foram influenciados pelo parcelamento do fertilizante fosfatado. A aplicação de $40 \%$ da dose de $\mathrm{P}$ em semeadura e do restante parcelado aos $35 \mathrm{DAE}$ reduziu a produtividade de algodão em caroço, não havendo efeito significativo nos demais parcelamentos.

PALAVRAS-CHAVE: Gossypium hirsutum L.; capulho; adubação fosfatada.

vel às plantas, pela rápida formação de complexos insolúveis com cátions, especialmente $\mathrm{Al}$ e Fe (Vance et al. 2003).

Para reduzir a adsorção do $\mathrm{P}$ aplicado via fertilizantes, uma das opções é aumentar a concentração do nutriente em determinado volume de solo (localização), a fim de diminuir a superfície de contato do mesmo com o fertilizante fosfatado (Büll et al.

1. Trabalho recebido em fev./2011 e aceito para publicação em fev./2012 ( ${ }^{\circ}$ registro: PAT 13152).

2. Universidade Federal de Viçosa, Instituto de Ciências Agrárias, Rio Paranaíba, MG, Brasil.

E-mails: leonardo.aquino@ufv.br, rosiane.aquino@ufv.br.

3. Universidade Federal de Viçosa, Departamento de Fitotecnia, Viçosa, MG, Brasil.E-mails: pgberger@ufv.br, tclima@gmail.com. 4. Universidade Federal de Viçosa, Departamento de Solos, Viçosa, MG, Brasil.E-mail: Julio_n2003@yahoo.com.br. 
2004). Como o fósforo se movimenta por difusão no solo, a localização do fertilizante deve estar próxima à semente, para garantir o crescimento adequado das raízes. No entanto, quando localizado muito próximo às sementes de algodão, pode reduzir o comprimento de raízes e a absorção de nutrientes pela planta (Souza et al. 2007). Além disto, em solos com alta disponibilidade de $\mathrm{P}$, o efeito da localização do fertilizante fosfatado, para aumento da eficiência de absorção, tende a ser menor, ou mesmo nulo, em comparação aos solos que apresentam baixa disponibilidade do nutriente (Büll et al. 2004).

Gonçalves et al. (1985) aplicaram $50 \mathrm{mg} \mathrm{kg}^{-1}$ de $\mathrm{P}$ em solos de diferentes classes e texturas, pobres em $\mathrm{P}$, e demonstraram que, em média, após 192 horas de contato do P com o solo, mais de $90 \%$ do $\mathrm{P}$ aplicado foi adsorvido. A velocidade da adsorção inicial se correlaciona com a formação de P não-lábil, a partir do P lábil (Novais \& Smyth 1999).

O parcelamento da adubação fosfatada favorece a produtividade e o efeito residual de $\mathrm{P}$ no solo, ao longo dos anos de cultivo (Silva et al. 1990, Resende et al. 2006). Em algodoeiro, a aplicação da dose de $726 \mathrm{~kg} \mathrm{ha}^{-1}$ de $\mathrm{P}_{2} \mathrm{O}_{5}$, parcelada ao longo de seis anos, no sulco de semeadura, ou no primeiro e quarto anos, a lanço, proporcionou maior produtividade e efeitos positivos na qualidade da fibra, quando comparada à aplicação a lanço, em dose única, no primeiro ano (Silva et al. 1990). Na cultura do milho, a aplicação parcelada de superfosfato triplo, termofosfato magnesiano, fosfato natural de Arad e fosfato natural de Araxá, no sulco de semeadura, promoveu maior produtividade, ao longo de três anos, quando comparada com a aplicação da mesma quantidade total aplicada no primeiro ano (Resende et al. 2006).

No algodoeiro, a demanda por P é alta do início da formação dos botões florais até a maturação (Frye \& Kairuz 1990). O P é importante especialmente para o pegamento e desenvolvimento da parte reprodutiva do algodoeiro (Rosolém \& Bastos 1997). Assim, o parcelamento da adubação fosfatada, ao diminuir o tempo de contato da fonte fosfatada solúvel com o solo, pode contribuir para diminuir a fixação de $P$ pelos coloides de argila. Maiores produtividades para uma mesma dose de $\mathrm{P}$, ou menores doses de $\mathrm{P}$ para as produtividades atualmente obtidas, podem ser alcançadas por meio do parcelamento do fertilizante fosfatado.

Neste contexto, objetivou-se, com este trabalho, avaliar o conteúdo de $\mathrm{P}$ na parte aérea e a produtividade de algodão em caroço, sob cultivo irrigado, com a aplicação parcelada de doses de $\mathrm{P}_{2} \mathrm{O}_{5}$, em Neossolo Quartzarênico.

\section{MATERIAL E MÉTODOS}

O experimento foi desenvolvido no município

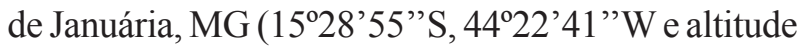
de $474 \mathrm{~m}$ ), em condições de campo. Utilizou-se a cultivar 'Delta Opal'. A semeadura foi realizada em $11 / 11 / 2008$, com espaçamento de $0,80 \mathrm{~m}$ entrelinhas, sendo aplicada a quantidade de sementes necessária para o estabelecimento de uma população de 100 mil plantas por hectare. O preparo do solo consistiu de subsolagem, aração e duas gradagens, como usualmente indicado para algodoeiro. O solo da área experimental, de textura arenosa, foi classificado como Neossolo Quartzarênico órtico típico (Embrapa 2006). Os atributos físicos e químicos do solo são apresentados na Tabela 1.

O delineamento experimental utilizado foi o de blocos ao acaso, em arranjo fatorial $(4 \times 3)+3$, com

Tabela 1. Características físico-químicas do solo do experimento, na camada 0-20 cm (Rio Paranaíba, MG, 2011).

\begin{tabular}{|c|c|}
\hline $\mathrm{pH}\left(\mathrm{H}_{2} \mathrm{O}, 1: 2,5\right)$ & 6,200 \\
\hline M.O. $\left(\mathrm{g} \mathrm{kg}^{-1}\right)$ & 5,000 \\
\hline $\mathrm{P}\left(\mathrm{mg} \mathrm{dm}^{-3}\right)$ & 22,000 \\
\hline $\mathrm{K}\left(\mathrm{mg} \mathrm{dm}^{-3}\right)$ & 73,000 \\
\hline $\mathrm{Ca}^{2+}\left(\mathrm{cmol}_{\mathrm{c}} \mathrm{dm}^{-3}\right)$ & 1,500 \\
\hline $\mathrm{Mg}^{2+}\left(\mathrm{cmol}_{\mathrm{c}} \mathrm{dm}^{-3}\right)$ & 0,400 \\
\hline $\mathrm{Al}^{3+}\left(\mathrm{cmol}_{\mathrm{c}} \mathrm{dm}^{-3}\right)$ & 0,000 \\
\hline $\mathrm{H}+\mathrm{Al}\left(\mathrm{cmol}_{\mathrm{c}} \mathrm{dm}^{-3}\right)$ & 2,400 \\
\hline Areia grossa $\left(\mathrm{g} \mathrm{kg}^{-1}\right)$ & 300,000 \\
\hline Areia fina $\left(\mathrm{g} \mathrm{kg}^{-1}\right)$ & 570,000 \\
\hline Silte $\left(\mathrm{g} \mathrm{kg}^{-1}\right)$ & 30,000 \\
\hline $\mathrm{T}\left(\mathrm{cmol}_{\mathrm{c}} \mathrm{dm}^{-3}\right)$ & 4,500 \\
\hline $\mathrm{S}\left(\mathrm{mg} \mathrm{dm} \mathrm{m}^{-3}\right)$ & 5,600 \\
\hline $\mathrm{B}\left(\mathrm{mg} \mathrm{dm}^{-3}\right)$ & 0,260 \\
\hline $\mathrm{Zn}\left(\mathrm{mg} \mathrm{dm}^{-3}\right)$ & 4,600 \\
\hline $\operatorname{Mn}\left(\mathrm{mg} \mathrm{dm}^{-3}\right)$ & 70,900 \\
\hline $\mathrm{Cu}\left(\mathrm{mg} \mathrm{dm}^{-3}\right)$ & 0,300 \\
\hline $\mathrm{Fe}\left(\mathrm{mg} \mathrm{dm}^{-3}\right)$ & 13,200 \\
\hline P-rem $\left(\mathrm{mg} \mathrm{L}^{-1}\right)$ & 50,200 \\
\hline Argila $\left(\mathrm{g} \mathrm{kg}^{-1}\right)$ & 100,000 \\
\hline Capacidade de campo $\left(\mathrm{kg} \mathrm{kg}^{-1}\right)$ & 0,100 \\
\hline Ponto de murcha $\left(\mathrm{kg} \mathrm{kg}^{-1}\right)$ & 0,044 \\
\hline \multicolumn{2}{|c|}{$\begin{array}{l}\text { P, } \mathrm{Zn}, \mathrm{Mn}, \mathrm{Cu} \text { e Fe: Mehlich - } 1 ; \mathrm{Ca}^{2+}, \mathrm{Mg}^{2+} \text { e } \mathrm{Al}^{1+}: \mathrm{KCl} 1 \mathrm{~mol} \mathrm{~L}^{-1} ; \mathrm{H}+\mathrm{Al} \\
\mathrm{Ca}(\mathrm{OAc})_{2} 2,5 \mathrm{~mol} \mathrm{~L} \mathrm{~L}^{-1}, \mathrm{pH} 7 ; \mathrm{S} \text { : Fosfato monocálcico em ácido acético; } \mathrm{B}: \text { Água } \\
\text { quente; Prem = Fósforo remanescente de uma solução } 60 \mathrm{mg} \mathrm{L}^{-1} \mathrm{de} \mathrm{Pem} \mathrm{CaCl} \\
10 \mathrm{mM} \text {, após agitação por } 1 \text { hora, com } 10 \mathrm{~cm}^{3} \text { de solo, e } 24 \text { horas de repouso; } \\
\text { M.O.: método da oxidoredução; Capacidade de campo e ponto de murcha: } \\
\text { umidade de equilíbrio nas tensões de }-10 \mathrm{kPa} \text { e }-1.500 \mathrm{kPa} \text {, respectivamente. }\end{array}$} \\
\hline
\end{tabular}


três repetições. Os fatores estudados foram doses de $\mathrm{P}_{2} \mathrm{O}_{5}\left(30 \mathrm{~kg} \mathrm{ha}^{-1}, 60 \mathrm{~kg} \mathrm{ha}^{-1}, 120 \mathrm{~kg} \mathrm{ha}^{-1}\right.$ e $\left.180 \mathrm{~kg} \mathrm{ha}^{-1}\right)$ e três formas de aplicação parcelada (P1: 80\% e 20\%; P2: $60 \%$ e $40 \%$; P3: $40 \%$ e $60 \%$ da dose do fertilizante fosfatado aplicada em semeadura e aos 35 dias após a emergência (DAE), respectivamente). Os três tratamentos adicionais foram: sem aplicação de $\mathrm{P}$ e doses de $60 \mathrm{~kg} \mathrm{ha}^{-1}$ e $120 \mathrm{~kg} \mathrm{ha}^{-1}$ de $\mathrm{P}_{2} \mathrm{O}_{5}$, distribuídas no sulco de semeadura. Estas duas doses foram utilizadas em semeadura, para comparar o efeito do parcelamento, em condições de baixa ou alta taxa de aplicação de adubo fosfatado.

Cada unidade experimental constituiu-se de cinco fileiras de $6,0 \mathrm{~m}$. A área útil das parcelas correspondeu às três fileiras centrais, sendo desconsiderados $0,50 \mathrm{~m}$ das extremidades. No tratamento com P aplicado de forma parcelada aos 35 DAE, incorporou-se o fertilizante a $0,10 \mathrm{~m}$ de profundidade e a $0,20 \mathrm{~m}$ da fileira de plantas. A fonte de P utilizada na semeadura e em cobertura foi o superfosfato triplo granulado, com $41 \%$ de $\mathrm{P}_{2} \mathrm{O}_{5}$.

A recomendação de corretivo e adubações, exceto fosfatadas, foi realizada de acordo com resultados de análise de solo, seguindo-se as recomendações propostas para a cultura pelo Ferticalc Algodoeiro (Possamai 2003). O Ferticalc é um sistema de recomendação de fertilizantes e corretivos baseado no balanço nutricional entre as quantidades de nutrientes requeridas pelos componentes vegetativos e reprodutivos e as quantidades disponibilizadas pelo solo.

$\mathrm{Na}$ semeadura, foram aplicados N, K, Zn e $\mathrm{B}$, nas doses de $12 \mathrm{~kg} \mathrm{ha}^{-1}, 25 \mathrm{~kg} \mathrm{ha}^{-1}, 2 \mathrm{~kg} \mathrm{ha}^{-1} \mathrm{e}$ $1 \mathrm{~kg} \mathrm{ha}^{-1}$, respectivamente. Em cobertura, $188 \mathrm{~kg} \mathrm{ha}^{-1}$ de $\mathrm{N}$ e $116 \mathrm{~kg} \mathrm{ha}^{-1}$ de $\mathrm{K}_{2} \mathrm{O}$ foram aplicados, parcelados aos 25,35 e 45 DAE. O N em semeadura e mais $63 \mathrm{~kg} \mathrm{ha}^{-1}$, aplicados em cobertura, foram supridos via sulfato de amônio. O restante da dose de $\mathrm{N}$ foi suprido via ureia. A fonte de potássio foi o KCl. Foram aplicados, via foliar, $5 \mathrm{~kg} \mathrm{ha}^{-1} \mathrm{de}$ Fertilis $38^{\circledR}$ (10\% de N; 3\% de Mg; $10 \%$ de S; 3\% de B; $2 \%$ de $\mathrm{Cu} ; 2 \%$ de Fe; $2 \%$ de $\mathrm{Mn} ; 0,1 \%$ de Mo; $8 \%$ de $\mathrm{Zn}$ ).

O manejo de plantas daninhas foi realizado pela aplicação dos herbicidas S-metolachlor + Trifluralin, em pré-emergência; Pyrithiobac Sodium e Fenaxiprop-p-ethyl, em pós-emergência; e flumioxazin + paraquat + S-metolachlor, em pós-emergência, com jato dirigido.

Foram realizadas aplicações dos inseticidas Spinosad, Endosulfan e Deltametrina, nas doses recomendadas para a cultura, para controle de insetos-praga. Realizaram-se duas aplicações de Piraclostrobina e Tebuconozole, para controle da Mancha-de-Ramulária.

As irrigações foram realizadas por sistema de aspersão convencional (Bernardo et al. 2006). $\mathrm{O}$ espaçamento entre aspersores foi de $12,0 \mathrm{~m} \mathrm{x}$ $12,0 \mathrm{~m}$. A lâmina média aplicada foi de $7,2 \mathrm{~mm} \mathrm{~h}^{-1}$. Avaliou-se a uniformidade pelo Coeficiente de Uniformidade de Christiansen (CUC), o qual foi de $83 \%$. Com os dados meteorológicos obtidos na estação meteorológica automática localizada a 200,0 m da área experimental, calculou-se a evapotranspiração de referência, com a aplicação da equação de Penman-Monteith. A evapotranspiração da cultura foi calculada multiplicando-se a evapotranspiração de referência pelos coeficientes da cultura (Bernardo et al. 2006). Quando a precipitação efetiva foi menor que a evapotranspiração da cultura, aplicou-se uma lâmina de água, necessária para elevar a umidade do solo à capacidade de campo.

Amostraram-se as plantas aos 50 DAE e 80 DAE, coincidindo com os estádios fenológicos de início de florescimento e crescimento pleno, com desenvolvimento de maçãs. Estes estádios foram escolhidos por serem as fases de crescimento pleno e estabilização do crescimento vegetativo, respectivamente.

Coletou-se a parte aérea de quatro plantas da área útil, as quais foram lavadas e tiveram as folhas (do ramo principal e dos ramos frutíferos) separadas dos caules, aos 50 DAE. Aos 80 DAE, separaram-se as folhas (do ramo principal e dos ramos frutíferos), os caules e as estruturas reprodutivas (botões florais, flores e frutos). Em seguida, cada órgão da planta foi seco em estufa, a $70^{\circ} \mathrm{C}$, até massa constante, e pesado. Após a secagem, o material vegetal foi triturado em moinho tipo Wiley e o teor de P determinado segundo Malavolta et al. (1997).

Calculou-se a quantidade acumulada em cada parte da planta (conteúdo), pelo produto entre a massa da matéria seca do órgão e o teor de $\mathrm{P}$ da respectiva parte da planta. A quantidade total absorvida (conteúdo de P) aos 50 DAE e 80 DAE foi obtida pela soma do conteúdo de $\mathrm{P}$ nas folhas, nos caules e nas estruturas reprodutivas.

Aos 80 DAE, realizou-se a contagem do número de estruturas reprodutivas (botões florais, flores e maçãs). Esta contagem foi realizada em dez plantas, escolhidas aleatoriamente na área útil da parcela. 
Coletou-se a folha índice (quinta folha completamente expandida do ápice para a base), conforme Silva (2008), de dez plantas da área útil de cada parcela, para determinação dos teores de $\mathrm{N}, \mathrm{P}, \mathrm{K}, \mathrm{Ca}, \mathrm{Mg}, \mathrm{S}$, $\mathrm{Cu}, \mathrm{Fe}, \mathrm{Mn}, \mathrm{Zn}$ e B. As folhas coletadas foram lavadas, secas e trituradas. Os teores de N, P, K, Ca, Mg, $\mathrm{S}, \mathrm{B}, \mathrm{Cu}, \mathrm{Fe}, \mathrm{Mn}$ e $\mathrm{Zn}$ foram determinados conforme descrito em Malavolta et al. (1997).

Realizou-se a desfolha utilizando-se carfentrazone-ethyl, associado a óleo mineral, aos 135 DAE. Procedeu-se à colheita aos $142 \mathrm{DAE}$, quando foram determinados o número e a massa dos capulhos de vinte plantas de cada parcela. A produtividade do algodão em caroço foi determinada após a colheita dos capulhos da área útil da parcela. Calculou-se a eficiência relativa da adubação fosfatada tomando-se, como referencial, a produção de algodão em caroço do tratamento sem adubação fosfatada (Resende et al. 2006), como se segue: Eficiência Relativa $=$ [Produtividade do tratamento com aplicação do fertilizante / Produtividade do tratamento sem aplicação do fertilizante] x 100 .

Os dados foram submetidos a análise de variância, utilizando-se o software estatístico SAEG versão 9.1 (SAEG 2007). Foi realizado desdobramento dos graus de liberdade dos fatores estudados. Realizaram-se análises de regressão para as doses de $\mathrm{P}_{2} \mathrm{O}_{5}$. Quando os modelos linear, quadrático, raiz quadrada ou cúbico não se ajustaram aos dados de pelo menos um dos parcelamentos, realizou-se a regressão, independentemente dos parcelamentos. Para avaliar o efeito do parcelamento, as aplicações parceladas de $60 \mathrm{~kg} \mathrm{ha}^{-1}$ ou $120 \mathrm{~kg} \mathrm{ha}^{-1}$ foram comparadas às respectivas doses aplicadas apenas em semeadura e à dose zero, pelo teste Dunnett, a 5\%.

\section{RESULTADOS E DISCUSSÃO}

Houve efeito das doses de P para a massa da parte aérea seca, aos 50 DAE (Figura 1a), e de estruturas reprodutivas secas, aos 80 DAE (Figura 1b). Não houve efeito de doses de $\mathrm{P}$ e de parcelamentos para a massa da parte aérea seca, aos $80 \mathrm{DAE}$. Nesta época, a média geral da massa da parte aérea seca foi de $7.153 \mathrm{~kg} \mathrm{ha}^{-1}$ (dados não apresentados). O P é importante para o pegamento e desenvolvimento da parte reprodutiva da planta. Este nutriente promove maior crescimento dos frutos e capulhos com maior massa (Rosolém \& Bastos 1997).
Não houve efeito de doses de $\mathrm{P}$ ou do parcelamento destas sobre o teor e conteúdo de P nas folhas, nos caules e nas estruturas reprodutivas, nas datas avaliadas (Tabela 2). Entretanto, houve incremento linear do conteúdo (quantidade acumulada) de P na parte aérea, aos 50 DAE e 80 DAE, em função das doses de $\mathrm{P}$. O incremento se deu independentemente das formas de aplicação parceladas (Figuras 2a e 2b). $\mathrm{O}$ algodoeiro possui alta demanda de $\mathrm{P}$, se comparado a outros cultivos anuais (Frye \& Kairuz 1990). Isto justifica o incremento linear no conteúdo de P, na parte aérea, com as doses de $\mathrm{P}$ aplicadas, mesmo em solo com disponibilidade média do nutriente (Alvarez V. et al. 1999).

O conteúdo de $\mathrm{P}$ na parte aérea, aos $50 \mathrm{DAE}$ e 80 DAE, das plantas que receberam os tratamentos com as aplicações parceladas de $60 \mathrm{~kg} \mathrm{ha}^{-1}$ ou $120 \mathrm{~kg} \mathrm{ha}^{-1}$ de $\mathrm{P}_{2} \mathrm{O}_{5}$, não diferiu do conteúdo daquelas que receberam aplicação tradicional, em semeadura (Tabela 3). O conteúdo de $\mathrm{P}$ na parte aérea, aos
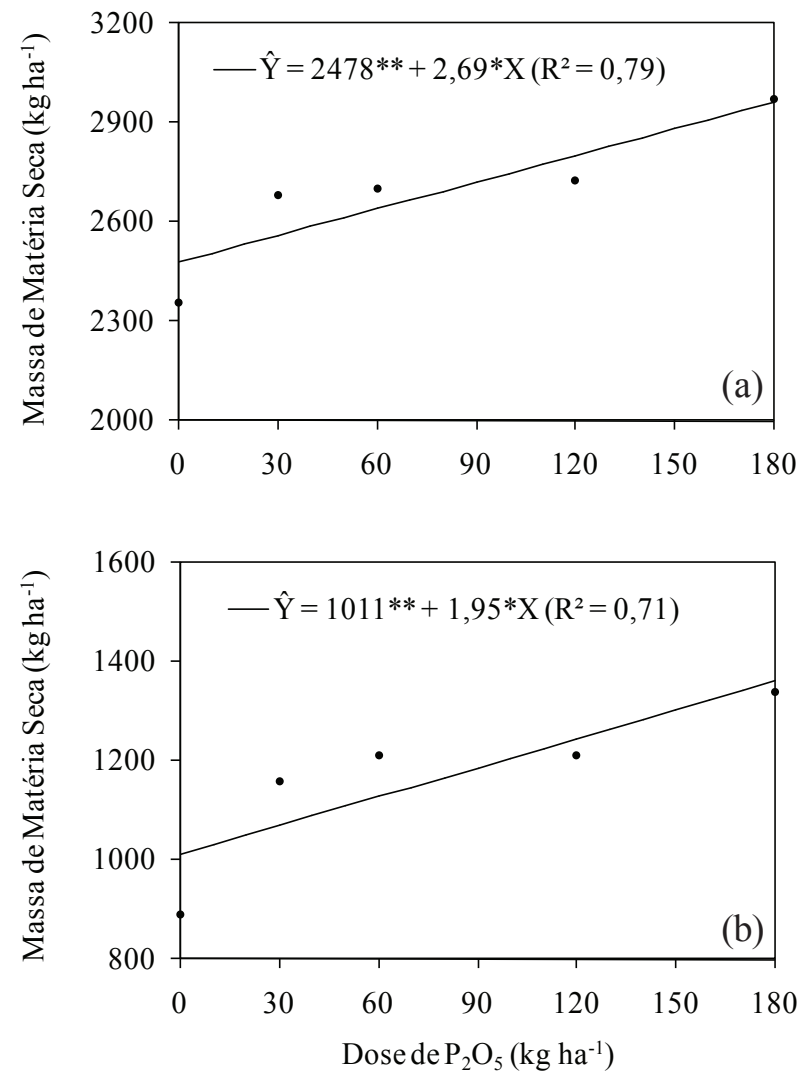

Figura 1. Massa da parte área seca (folha + caule) do algodoeiro, aos 50 DAE (a), e de estruturas reprodutivas secas, aos 80 DAE (b), em função das doses de $\mathrm{P}_{2} \mathrm{O}_{5}$ (Rio Paranaíba, MG, 2011). 
Tabela 2. Teor e conteúdo de P nas folhas, caules e estruturas reprodutivas secas do algodoeiro, aos 50 DAE e 80 DAE (Rio Paranaíba, MG, 2011).

\begin{tabular}{|c|c|c|c|c|c|c|}
\hline \multirow{2}{*}{ Órgão da planta } & \multicolumn{3}{|c|}{ Teor de $\mathrm{P}$} & \multicolumn{3}{|c|}{ Conteúdo de P } \\
\hline & $\mathrm{g} \mathrm{kg}^{-1}$ & $\mathrm{~F}$ & CV $(\%)$ & $\mathrm{kg} \mathrm{ha}^{-1}$ & $\mathrm{~F}$ & CV $(\%)$ \\
\hline & \multicolumn{6}{|c|}{$50 \mathrm{DAE}$} \\
\hline Folha & 5,2 & $0,61^{\mathrm{ns}}$ & 10,7 & 8,6 & $0,89^{\text {ns }}$ & 31,1 \\
\hline Caule & 2,5 & $0,44^{\mathrm{ns}}$ & 13,6 & 2,5 & $0,64^{\mathrm{ns}}$ & 28,7 \\
\hline Folha & 3,6 & $0,92^{\text {ns }}$ & 13,6 & 11,8 & $0,41^{\mathrm{ns}}$ & 25,9 \\
\hline Caule & 2,0 & $0,49^{\text {ns }}$ & 13,7 & 5,9 & $0,80^{\text {ns }}$ & 26,8 \\
\hline Estruturas reprodutivas & 5,9 & $0,34^{\mathrm{ns}}$ & 9,4 & 6,9 & $0,19^{\text {ns }}$ & 26,2 \\
\hline
\end{tabular}

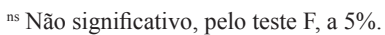

Tabela 3. Efeito da aplicação parcelada do fertilizante fosfatado no algodoeiro sobre o número de estruturas reprodutivas, teor e conteúdo de fósforo $(\mathrm{P})$, massa e número de capulhos, eficiência relativa da adubação fosfatada e produtividade de algodão em caroço (Rio Paranaíba, MG, 2011).

\begin{tabular}{|c|c|c|c|c|c|c|c|c|c|c|}
\hline Doses de $\mathrm{P}_{2} \mathrm{O}_{5}\left(\mathrm{~kg} \mathrm{ha}^{-1}\right)$ & 0 & $\longrightarrow$ & 6 & 0 & 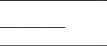 & 0 & 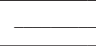 & -1 & $120-$ & \\
\hline Parcelamentos & & PS & P1 & P2 & P3 & & PS & P1 & P2 & P3 \\
\hline Número de estruturas reprodutivas & $98^{\mathrm{ns}}$ & 119 & $106^{\mathrm{ns}}$ & $108^{\mathrm{ns}}$ & $106^{\mathrm{ns}}$ & $98^{\mathrm{ns}}$ & 106 & $102^{\mathrm{ns}}$ & $99^{\text {ns }}$ & $101^{\mathrm{ns}}$ \\
\hline Conteúdo de P na parte aérea ${ }^{1}$ - 50 DAE $\left(\mathrm{kg} \mathrm{ha}^{-1}\right)$ & $7,8^{\mathrm{ns}}$ & 8,8 & $10,0^{\mathrm{ns}}$ & $9,6^{\mathrm{ns}}$ & $11,9^{\text {ns }}$ & $7,8^{\mathrm{ns}}$ & 13,2 & $9,3^{\mathrm{ns}}$ & $10,3^{\text {ns }}$ & $9,1^{\mathrm{ns}}$ \\
\hline Conteúdo de P na parte aérea ${ }^{2}-80$ DAE $\left(\mathrm{kg} \mathrm{ha}^{-1}\right)$ & $20,1^{\mathrm{ns}}$ & 23,9 & $21,5^{\text {ns }}$ & $26,8^{\mathrm{ns}}$ & $25,0^{\mathrm{ns}}$ & $20,1^{\mathrm{ns}}$ & 25,9 & $25,8^{\mathrm{ns}}$ & $22,7^{\mathrm{ns}}$ & $24,2^{\mathrm{ns}}$ \\
\hline Teor de P na folha índice - 80 DAE (dag $\left.\mathrm{kg}^{-1}\right)$ & $0,34^{\mathrm{ns}}$ & 0,34 & $0,36^{\mathrm{ns}}$ & $0,37^{\mathrm{ns}}$ & $0,31^{\mathrm{ns}}$ & $0,34^{\mathrm{ns}}$ & 0,38 & $0,42^{\text {ns }}$ & $0,42^{\mathrm{ns}}$ & $0,41^{\mathrm{ns}}$ \\
\hline Massa de Capulho $(\mathrm{g})$ & $5,6^{\mathrm{ns}}$ & 6,6 & $5,8^{\mathrm{ns}}$ & $6,1^{\mathrm{ns}}$ & $6,1^{\mathrm{ns}}$ & $5,6^{\mathrm{ns}}$ & 6,0 & $5,9^{\text {ns }}$ & $6,2^{\mathrm{ns}}$ & $5,5^{\mathrm{ns}}$ \\
\hline Número de capulhos por planta & $7,2^{\text {ns }}$ & 7,7 & $9,1^{\mathrm{ns}}$ & $8,5^{\mathrm{ns}}$ & $7,2^{\mathrm{ns}}$ & $7,2 *$ & 9,5 & $9,5^{\mathrm{ns}}$ & $9,1^{\text {ns }}$ & $9,4^{\mathrm{ns}}$ \\
\hline Eficiência relativa da adubação fosfatada (\%) & $100^{*}$ & 127 & $132^{\text {ns }}$ & $130^{\mathrm{ns}}$ & $110^{*}$ & $100 *$ & 143 & $142^{\mathrm{ns}}$ & $141^{\mathrm{ns}}$ & $129 *$ \\
\hline Produtividade de algodão em caroço $\left(\mathrm{kg} \mathrm{ha}^{-1}\right)$ & $4.136^{*}$ & 5.252 & $5.459^{\mathrm{ns}}$ & $5.386^{\mathrm{ns}}$ & $4.549 *$ & $4.136^{*}$ & 5.905 & $5.877^{\mathrm{ns}}$ & $5.826^{\mathrm{ns}}$ & $5.321 *$ \\
\hline
\end{tabular}
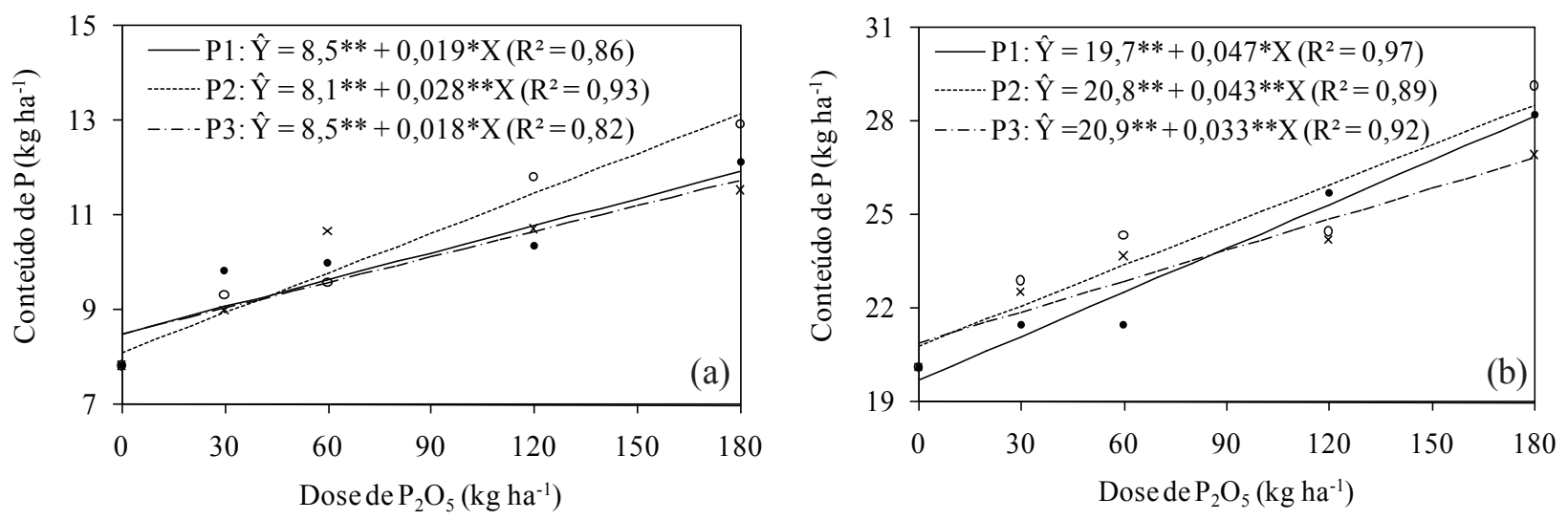

Figura 2. Conteúdo de P na parte aérea do algodoeiro, aos 50 DAE (a) e 80 DAE (b), em função das doses de $\mathrm{P}_{2} \mathrm{O}_{5}$ e de parcelamentos (P) do fertilizante fosfatado (Rio Paranaíba, MG, 2011). • P1 (80\% da dose de P em semeadura e $20 \%$ aos 35 DAE); ${ }^{\circ} \mathrm{P} 2$ (60\% da dose de P em semeadura e 40\% aos $35 \mathrm{DAE}) ;{ }^{x} \mathrm{P} 3$ (40\% da dose de P em semeadura e $60 \%$ aos $\left.35 \mathrm{DAE}\right)$.

$80 \mathrm{DAE}$, foi de, aproximadamente, $25 \mathrm{~kg} \mathrm{ha}^{-1}$, com a aplicação de $60 \mathrm{~kg} \mathrm{ha}^{-1}$ ou $120 \mathrm{~kg} \mathrm{ha}^{-1}$ de $\mathrm{P}_{2} \mathrm{O}_{5}$. Este conteúdo é inferior ao observado por Possamai (2003), que estimou a demanda de P em $32 \mathrm{~kg} \mathrm{ha}^{-1}$, para produzir $4.800 \mathrm{~kg} \mathrm{ha}^{-1}$ de algodão em caroço.
Comparativamente aos dados de Possamai (2003), a menor absorção de P pode estar relacionada à menor massa da parte aérea seca produzida no experimento para a produtividade alcançada e à época de amostragem. Após os $80 \mathrm{DAE}$, quando as plantas não 
foram mais amostradas, significativas quantidades de $\mathrm{P}$, possivelmente, foram absorvidas. $\mathrm{O}$ algodoeiro mantém alta absorção de $\mathrm{P}$, durante boa parte de seu ciclo, resultando em elevadas quantidades absorvidas do nutriente (Frye \& Kairuz 1990).

Houve aumento no teor de P na folha índice, aos 80 DAE, em função das doses de $\mathrm{P}$ aplicadas parceladamente (Figura 3a). Os teores estimados de $\mathrm{P}$ na folha índice, aos $80 \mathrm{DAE}$, correspondentes às máximas produtividades, foram $3,8 \mathrm{~g} \mathrm{~kg}^{-1}, 3,8 \mathrm{~g} \mathrm{~kg}^{-1}$ e $4,1 \mathrm{~g} \mathrm{~kg}^{-1}$ de massa seca, para os parcelamentos $\mathrm{P} 1$, $\mathrm{P} 2$ e $\mathrm{P} 3$, respectivamente. A forma de aplicação das doses $60 \mathrm{~kg} \mathrm{ha}^{-1}$ e $120 \mathrm{~kg} \mathrm{ha}^{-1}$ de $\mathrm{P}_{2} \mathrm{O}_{5}$, parceladas ou apenas na semeadura, não influenciou o teor de P na folha índice (Tabela 3).

Os teores de P na folha índice, independentemente dos parcelamentos estudados, estiveram próximos ao limite superior, para a faixa considerada adequada à cultura do algodão, que varia de 2,0 dag kg-1 a 4,5 dag kg-1 (Possamai 2003, Silva 2008). Os valores próximos ao limite superior da faixa citada estão relacionados ao solo da área experimental, que apresenta baixo fator capacidade de $\mathrm{P}$, indicado pelo alto P-remanescente (Alvarez V. et al. 2000). Solos com menor fator capacidade apresentam maior nível crítico de determinado elemento, para certo nível de produtividade, quando comparados aos solos de maior fator capacidade, especialmente no caso de elementos menos móveis, como o P (Muniz et al. 1985).

Não houve efeito de doses de $\mathrm{P}$ ou de parcelamentos sobre os teores de $\mathrm{N}, \mathrm{K}, \mathrm{Ca}, \mathrm{Mg}, \mathrm{S}, \mathrm{Cu}, \mathrm{Fe}$, $\mathrm{Mn}, \mathrm{Zn}$ e B, na folha índice, aos 80 DAE (Tabela 4). Os teores de $\mathrm{N}, \mathrm{K}$ e $\mathrm{Mg}$ ficaram dentro da faixa de concentração considerada adequada para a cultura (Silva 2008), mas no limite inferior desta, para produtividades em torno de $4.800 \mathrm{~kg} \mathrm{ha}^{-1}$ (Possamai 2003). Os teores de $\mathrm{Ca}$ e de $\mathrm{S}$ foram superiores aos valores referenciais citados por Silva (2008) e Possamai (2003), para produtividade de $4.800 \mathrm{~kg} \mathrm{ha}^{-1}$. A relação Ca:Mg, no solo da área experimental, aos $80 \mathrm{DAE}$, estava em 4,3:1. A maior relação $\mathrm{Ca}: \mathrm{Mg}$ e $\mathrm{Ca}: \mathrm{K}$
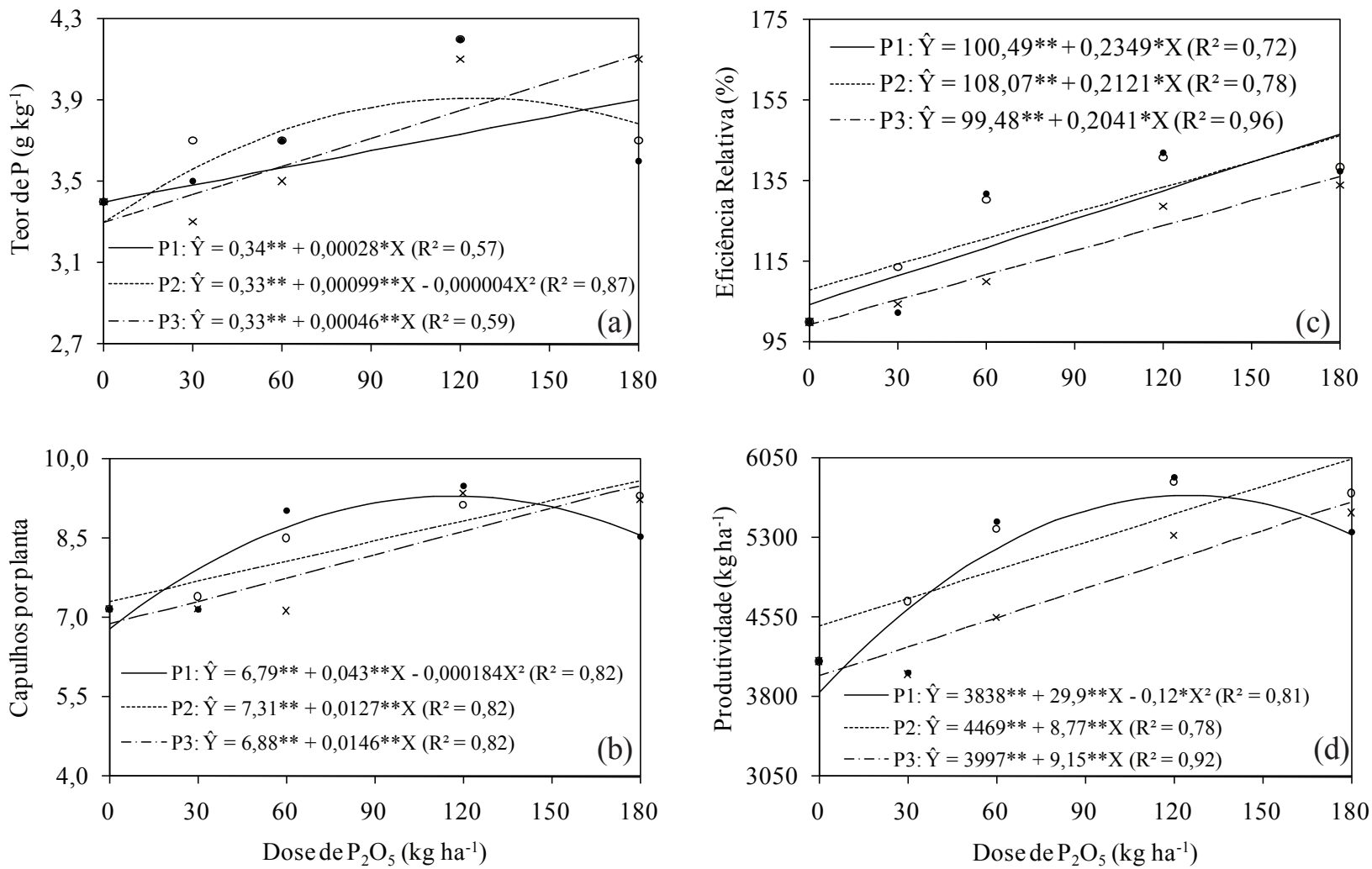

Figura 3. Teor de P na folha índice, aos 80 DAE (a), número de capulhos por planta (b), eficiência relativa da adubação fosfatada (c) e produtividade de algodão em caroço (d), em função de doses de $\mathrm{P}_{2} \mathrm{O}_{5}$ e parcelamentos $(\mathrm{P})$ do fertilizante fosfatado, no algodoeiro (Rio Paranaíba, MG, 2011). • P1 (80\% da dose de P em semeadura e 20\% aos 35 DAE); ${ }^{\circ} \mathrm{P} 2(60 \%$ da dose de P em semeadura e $40 \%$ aos 35 DAE); ${ }^{x}$ P3 (40\% da dose de P em semeadura e $60 \%$ aos 35 DAE). 
Tabela 4. Teor de nutrientes na folha índice do algodoeiro, aos 80 dias após a semeadura (Rio Paranaíba, MG, 2011).

\begin{tabular}{|c|c|c|c|c|c|c|c|c|c|c|}
\hline \multirow{2}{*}{ Nutriente } & $\mathrm{N}$ & $\mathrm{K}$ & $\mathrm{Ca}$ & $\mathrm{Mg}$ & $\mathrm{S}$ & $\mathrm{Cu}$ & $\mathrm{Fe}$ & $\mathrm{Mn}$ & $\mathrm{Zn}$ & B \\
\hline & \multicolumn{5}{|c|}{$\mathrm{g} \mathrm{kg}^{-1}$} & \multicolumn{5}{|c|}{$\mathrm{mg} \mathrm{kg}^{-1}$} \\
\hline Teor & 33,1 & 13,5 & 46,5 & 3,7 & 9,9 & 13,80 & 71,52 & 424,42 & 130,03 & 38,28 \\
\hline $\mathrm{F}$ & $0,98^{\text {ns }}$ & $0,56^{\mathrm{ns}}$ & $1,02^{\mathrm{ns}}$ & $0,65^{\text {ns }}$ & $1,05^{\mathrm{ns}}$ & $0,33^{\mathrm{ns}}$ & $0,89^{\text {ns }}$ & $0,71^{\mathrm{ns}}$ & $0,96^{\mathrm{ns}}$ & $0,21^{\mathrm{ns}}$ \\
\hline CV (\%) & 11,3 & 14,6 & 5,8 & 12,9 & 10,5 & 17,6 & 24,9 & 25,4 & 13,6 & 21,1 \\
\hline
\end{tabular}

ns Não significativo, pelo teste $\mathrm{F}$, a $5 \%$.

contribuiu para os maiores valores foliares de $\mathrm{Ca}$ e menores de $\mathrm{Mg}$ e $\mathrm{K}$. $\mathrm{O}$ teor de $\mathrm{S}$ acima do adequado deveu-se à elevação da sua disponibilidade, causada pela aplicação de $40 \%$ da dose de $\mathrm{N}$, na forma de sulfato de amônio, o qual contém $24 \%$ de S.

Quanto aos micronutrientes, os teores de $\mathrm{Cu}$ e de B ficaram dentro da faixa de concentração considerada adequada para o algodoeiro; os de $\mathrm{Mn}$ e Zn acima; e os de Fe abaixo (Silva 2008). Os teores de Mn e Zn acima da concentração adequada podem ser devidos ao encharcamento do solo, que ocorreu na fase inicial da cultura, e ao fertilizante foliar aplicado ( $8 \%$ de $\mathrm{Zn})$, respectivamente. O encharcamento do solo aumenta a concentração da forma $\mathrm{Mn}^{2+}$ absorvida pelas plantas. O menor teor de Fe pode ser atribuído à pobreza deste no solo da área experimental e à disponibilidade de $\mathrm{P}$ no solo, classificada como média (Alvarez V. et al. 1999). O aumento da disponibilidade de $\mathrm{P}$ no solo pode levar à formação de compostos de baixa solubilidade de P ligado ao Fe, reduzindo a disponibilidade deste último às plantas (Vance et al. 2003).

Houve interação das doses de $\mathrm{P} x$ parcelamento, para o número de capulhos por planta (Figura 3b). Em todos os parcelamentos, o aumento da dose de $\mathrm{P}$ incrementou o número de capulhos por planta. Doses de $\mathrm{P}$ ou parcelamento não aumentaram o número de estruturas reprodutivas, aos $80 \mathrm{DAE}$, e a massa de capulho (Tabela 3). Entretanto, o P aumenta o pegamento das estruturas reprodutivas, o que reflete em maior número de capulhos por planta na colheita e, por conseguinte, em maior produtividade (Silva et al. 1990, Rosolém \& Bastos 1997).

Houve aumento linear na eficiência relativa da fertilização fosfatada, ou seja, acréscimo de produtividade do produto comercial (algodão em caroço), promovido pela aplicação do fertilizante, em função das doses de $\mathrm{P}$ aplicadas para todos os parcelamentos (Figura 3c). Na forma de aplicação parcelada P3 (60 kg ha-1 e $120 \mathrm{~kg} \mathrm{ha}^{-1}$ de $\left.\mathrm{P}_{2} \mathrm{O}_{5}\right)$, houve redução da eficiência relativa da adubação fosfatada, em comparação com a aplicação em semeadura (Tabela 3).

Os valores de eficiência relativa, exceto para o parcelamento $\mathrm{P} 3$, superaram os observados por Resende et al. (2006), em solo com elevado fator capacidade de $\mathrm{P}$, submetido ao cultivo de milho adubado com superfosfato triplo. A eficiência relativa depende de características relacionadas ao grau de tamponamento do solo ao nutriente e da eficiência de absorção e utilização da espécie e das cultivares de cada espécie (Vance et al. 2003, Resende et al. 2006).

As produtividades máximas de algodão em caroço estimadas foram de $5.700 \mathrm{~kg} \mathrm{ha}^{-1}, 6.047 \mathrm{~kg} \mathrm{ha}^{-1}$ e $5.644 \mathrm{~kg} \mathrm{ha}^{-1}$, nos parcelamentos P1, P2 e P3, respectivamente (Figura 3d). Estas produtividades máximas estimadas foram obtidas com a maior dose de $\mathrm{P}$ testada nos parcelamentos $\mathrm{P} 2$ e P3 e com a dose $125 \mathrm{~kg} \mathrm{ha}^{-1} \mathrm{de}_{2} \mathrm{O}_{5}$, no parcelamento $\mathrm{P} 1$. A aplicação parcelada de $60 \mathrm{~kg} \mathrm{ha}^{-1}$ e $120 \mathrm{~kg} \mathrm{ha}^{-1}$ de $\mathrm{P}_{2} \mathrm{O}_{5}$, em comparação à aplicação apenas em semeadura (PS), não incrementou a produtividade do algodão em caroço (Tabela 3). Assim, nos tratamentos em que se aplicou a maior parte das doses em cobertura (P3), houve menor disponibilidade do elemento no solo, na fase crítica de formação do sistema radicular. $\mathrm{O}$ $\mathrm{P}$ tem grande importância na fase inicial da cultura, especialmente para o crescimento do sistema radicular (Grant et al. 2001).

Diversas técnicas, como a granulação de fertilizantes fosfatados, aplicação localizada à linha de semeadura e uso de fontes de menor solubilidade, têm sido utilizadas, no intuito de aumentar a absorção do $\mathrm{P}$ aplicado e a produtividade dos cultivos. Tais técnicas têm maior efeito em solos com maior fator capacidade de $\mathrm{P}$ e com baixa disponibilidade do P (Horowitz \& Meurer 2003, Büll et al. 2004, Prochnow et al. 2006). Isto sugere que o parcelamento do fertilizante fosfatado, como técnica para aumento da eficiência do mesmo, deve ter efeito em solos de maior fator capacidade de $\mathrm{P}$ e de baixa disponibilidade de $\mathrm{P}$. 


\section{CONCLUSÕES}

1. A aplicação parcelada da dose $60 \mathrm{~kg} \mathrm{ha}^{-1}$ ou $120 \mathrm{~kg} \mathrm{ha}^{-1}$ de $\mathrm{P}_{2} \mathrm{O}_{5}$ não altera o conteúdo de $\mathrm{P}$ na parte aérea, aos 50 DAE e 80 DAE, em comparação à aplicação tradicional em semeadura.

2. Em Neossolo Quartazarênico, com disponibilidade de P classificada como média, não há efeito do parcelamento da adubação fosfatada, para aplicações de $80 \%$ e $60 \%$ na semeadura e o restante parcelado, enquanto, para aplicação de $40 \%$ da dose de $\mathrm{P}$ em semeadura e do restante aos $35 \mathrm{DAE}$, há redução da produtividade de algodão em caroço.

3. Não há benefício para a produtividade do algodoeiro, ao se aplicar o fertilizante fosfatado de forma parcelada (semeadura e $35 \mathrm{DAE}$ ), em comparação à aplicação tradicional em semeadura.

\section{AGRADECIMENTOS}

À Fundação de Amparo à Pesquisa do Estado de Minas Gerais (Fapemig), pelo auxílio financeiro, e ao Conselho Nacional de Desenvolvimento Científico e Tecnológico (CNPq), pela concessão de bolsa de doutorado ao primeiro autor.

\section{REFERÊNCIAS}

ALVAREZ V., V. H. et al. Determinação e uso do fósforo remanescente. Boletim Informativo da Sociedade Brasileira de Ciência do Solo, Viçosa, v. 25, n. 1, p. 27 32, 2000.

ALVAREZ V., V. H. et al. Interpretação dos resultados das análises de solos. In: RIBEIRO, A. C.; GUIMARÃES, P. T. G.; ALVAREZ V., V. H. (Eds.). Recomendação para $o$ uso de corretivos e fertilizantes em Minas Gerais: $5^{\mathrm{a}}$ aproximação. Viçosa: Comissão de Fertilidade do Solo do Estado de Minas Gerais, 1999. p. 25-32.

BERNARDO, S.; SOARES, A. A.; MANTOVANI, E. C. Manual de irrigação. Viçosa: UFV, 2006.

BÜLL, L. T. et al. Doses and forms of application of phosphorus in vernalized garlic. Scientia Agricola, Piracicaba, v. 61, n. 5, p. 516-521, 2004.

EMPRESA BRASILEIRA DE PESQUISA AGROPECUÁRIA (Embrapa). Sistema brasileiro de classificação de solos. Brasília, DF: Embrapa, 2006.

FRYE, I. A. A.; KAIRUZ, I. A. G. Manejo de suelos y uso de fertilizantes. In: FEDERACIÓN NACIONAL DE ALGODOEIROS. Bases técnicas para el cultivo del algodón en Colombia. Bogotá: Guadalupe, 1990. p. 133202.
GONÇALVES, J. L. M. et al. Cinética de adsorção de fósforo em solos de Cerrado. Revista Brasileira de Ciência do Solo, Viçosa, v. 9, n. 1, p. 107-111, 1985.

GRANT, C. A. et al. A importância do fósforo no desenvolvimento inicial da planta. Informações Agronômicas, Piracicaba, v. 95, n. 1, p. 1-5, 2001.

HOROWITZ, N.; MEURER, E. J. Eficiência de dois fosfatos naturais farelados em função do tamanho da partícula. Ciência Rural, Santa Maria, v. 33, n. 1, p. 4147, 2003.

MALAVOLTA, E.; VITTI, G. C.; OLIVEIRA, S. A. Princípios, métodos e técnicas de avaliação do estado nutricional. In: MALAVOLTA, E. (Ed.). Avaliação do estado nutricional de plantas: princípios e aplicações. 2. ed. Piracicaba: Potafos, 1997. p. 115-230.

MUNIZ, A. S. et al. Nível crítico de fósforo na parte aérea da soja com variável do fator capacidade de fósforo do solo. Revista Brasileira de Ciência do Solo, Viçosa, v. 9, n. 1, p. 237-243, 1985.

NOVAIS, R. F.; SMYTH, T. J. Fósforo em solo e planta em condições tropicais. Viçosa: UFV, 1999.

POSSAMAI, J. M. Sistema de recomendação de corretivos e fertilizantes para o cultivo do algodoeiro. $2003.91 \mathrm{f}$. Dissertação (Mestrado em Solos e Nutrição de Plantas)Universidade Federal de Viçosa, Viçosa, 2003.

PROCHNOW, L. I. et al. Effectiveness of phosphate fertilizers of different water solubilities in relation to soil phosphorus adsorption. Scientia Agricola, Piracicaba, v. 63, n. 4, p. 333-340, 2006.

RESENDE, A. V. et al. Fontes e modos de aplicação de fósforo para o milho em solo cultivado da região do Cerrado. Revista Brasileira de Ciência do Solo, Viçosa, v. 30, n. 3, p. 453-466, 2006.

ROSOLÉM, C. A.; BASTOS, G. B. Deficiências minerais no cultivar de algodão IAC 22. Bragantia, Campinas, v. 56, n. 2, p. 377-387, 1997.

SAEG: sistema para análises estatísticas. Versão 9.1. Viçosa: UFV, 2007.

SILVA, M. A. C. Diagnose foliar em algodão. In: PRADO, R. M. et al. (Eds.). Nutrição de plantas: diagnose foliar em grandes culturas. Jaboticabal: FCAV, 2008. p. 251-266.

SILVA, N. M. et al. Modo e época de aplicação de fosfatos na produção e outras características do algodoeiro. Bragantia, Campinas, v. 49, n. 1, p. 157-170, 1990.

SOUZA, F. S; FARINELLI, R.; ROSOLÉM, C. A. Desenvolvimento radicular do algodoeiro em resposta à localização do fertilizante. Revista Brasileira de Ciência do Solo, Viçosa, v. 31, n. 2, p. 387-392, 2007.

VANCE, C. P.; STONE, C. U.; ALLAN, D. L. Phosphorus acquisition and use: critical adaptations by plants for securing a nonrenewable resource. New Phytologist, Lancaster, v. 157, n. 1, p. 423-447, 2003. 